\title{
Oligomeric ricinoleic acid preparation promoted by an efficient and recoverable Brønsted acidic ionic liquid
}

\author{
Fei You ${ }^{1}$, Xing He${ }^{1}$, Song Gao ${ }^{1}$, Hong-Ru Li ${ }^{* 1,2}$ and Liang-Nian $\mathrm{He}^{* 1}$
}

\author{
Full Research Paper \\ Address: \\ ${ }^{1}$ State Key Laboratory and Institute of Elemento-Organic Chemistry, \\ College of Chemistry, Nankai University, Tianjin 300071, China and \\ ${ }^{2}$ College of Pharmacy, Nankai University, Tianjin 300353, China \\ Email: \\ Hong-Ru Li - lihongru@nankai.edu.cn; Liang-Nian $\mathrm{He}^{*}$ - \\ heln@nankai.edu.cn \\ * Corresponding author \\ Keywords: \\ bio-lubricant; ionic liquids; oligomeric ricinoleic acid; ricinoleic acid; \\ sustainable catalysis
}

\begin{abstract}
Raw material from biomass and green preparation processes are the two key features for the development of green products. As a bio-lubricant in metalworking fluids, estolides of ricinoleic acid are considered as the promising substitute to mineral oil with a favorable viscosity and viscosity index. Thus, an efficient and sustainable synthesis protocol is urgently needed to make the product really green. In this work, an environment-friendly Brønsted acidic ionic liquid (IL) 1-butanesulfonic acid diazabicyclo[5.4.0] undec-7-ene dihydrogen phosphate $\left(\left[\mathrm{HSO}_{3}-\mathrm{BDBU}_{2} \mathrm{H}_{2} \mathrm{PO}_{4}\right)\right.$ was developed as the efficient catalyst for the production of oligomeric ricinoleic acid from ricinoleic acid under solvent-free conditions. The reaction parameters containing reaction temperature, vacuum degree, amount of catalyst and reaction time were optimized and it was found that the reaction under the conditions of $190{ }^{\circ} \mathrm{C}$ and $50 \mathrm{kPa}$ with $15 \mathrm{wt} \%$ of the $\left[\mathrm{HSO}_{3}-\mathrm{BDBU}\right] \mathrm{H}_{2} \mathrm{PO}_{4}$ related to ricinoleic acid can afford a qualified product with an acid value of $51 \mathrm{mg} \mathrm{KOH} / \mathrm{g}$ (which corresponds to the oligomerization degree of 4) after $6 \mathrm{~h}$. Furthermore, the acid value of the product can be adjusted by regulating the reaction time, implying this protocol can serve as a versatile method to prepare the products with different oligomerization degree and different applications. The other merit of this protocol is the facile product separation by stratification and decantation ascribed to the immiscibility of the product and catalyst at room temperature. It is also worth mentioning that the IL catalyst can be used at least for five cycles with high catalytic activity. As a result, the protocol based on the IL catalyst, i.e. $\left[\mathrm{HSO}_{3}-\mathrm{BDBU}\right] \mathrm{H}_{2} \mathrm{PO}_{4}$ shows great potential in industrial production of oligomeric ricinoleic acid from ricinoleic acid.
\end{abstract}

\section{Introduction}

In recent years, the biomass has attracted much attention due to its abundance, renewability and potential of conversion to useful chemicals. It can't be denied that the diverse transformation and utilization of biomass provides an alternative avenue to liberate us from the reliance on petroleum resource [1]. Nowadays, fuels, fine chemicals and functional molecules/materials 
can be derived from biomass such as lignocellulose and plant oils $[2,3]$, wherein the plant oils play an important role in the polymer industry [4]. Especially, the characteristics of nonvolatility and biodegradability make plant oil the most promising material to develop functional polymeric materials with superior performance [5-7].

Castor oil is one kind of nonedible oil and can be extracted from the seeds of the castor bean plant. Globally, around one million tons of castor seeds are produced every year and the leading producing areas are India, China, and Brazil [8]. The castor oil has long been used as purgative or laxative to counter constipation and nowadays it is used commercially as a highly renewable resource for the chemical industry $[9,10]$. Numerous platform chemicals such as ricinoleic acid and undecylenic acid can be prepared from castor oil, wherein ricinoleic acid is a crucial platform chemical for derivation of useful chemicals [11-14].

Ricinoleic acid can be easily prepared by hydrolysis of castor oil [15]. The presence of both hydroxy and carboxy groups in the molecule of ricinoleic acid enables it to undergo intermolecular esterification, thus resulting in the formation of the oligomeric ricinoleic acid. The oligomeric ricinoleic acid with different acid value (which is an indirect index for oligomerization degree) has different applications. For example, as an additive in shampoos, the oligomeric ricinoleic acid with an acid value of $60-90 \mathrm{mg} \mathrm{KOH} / \mathrm{g}$ is required while for cosmetic formulations, an acid value of $20-40 \mathrm{mg} \mathrm{KOH} / \mathrm{g}$ is suitable [1619]. The oligomeric ricinoleic acid can also be used as lubricant for metal cutting oils due to its appropriate viscosity, good adsorptivity and film formation ability on metal surfaces. Furthermore, the biodegradability of these estolides in the environment makes them attractive as green products.

In parallel with the increasing demand for high-quality oligomeric ricinoleic acid, the synthetic method has kept on developing. Traditionally, $p$-toluenesulfonic or sulfuric acid are used as catalysts for the preparation of oligomeric ricinoleic acid. However, the equipment corrosion and the tedious workup process are inevitable, which reduce the process efficiency. Moreover, the byproduct formation and the resulting product coloration reduce the product quality. To address the above issues, the enzyme catalysis is proposed accordingly. Nevertheless, the high cost, low efficiency and operational unstability of enzymatic reaction make it difficult to industrial production [20-25]. Very recently, tin(II) 2-ethylhexanoate has been reported as an efficient catalyst for the synthesis of oligomeric ricinoleic acid [19]. Unfortunately, the separation of oligomeric ricinoleic acid and the recovery of the catalyst still encounters difficulties. Therefore, it is urgently desirable to develop an efficient, green and recyclable catalyst and design simple operating procedures for the preparation of estolides oligomeric ricinoleic acid.

Ionic liquids (ILs) have been proved to be efficient catalysts in various organic syntheses due to the designable structure, tunable properties as well as superior solubility [26,27]. Furthermore, the thermal stability and negligible vapor pressure of ILs can facilitate the product separation after reaction. To the best of our knowledge, the IL 1-butylsulfonic-3methylimidazolium tosylate $\left(\left[\mathrm{HSO}_{3}-\mathrm{BMim}\right] \mathrm{TS}\right)$ can be used as catalyst in the synthesis of oligomeric ricinoleic acid, the estolide with an acid value of $48 \pm 2.5 \mathrm{mg} \mathrm{KOH} / \mathrm{g}$ was obtained after $14 \mathrm{~h}$ [28]. Nevertheless, the product separation and catalyst reusability have not yet been investigated until now.

Based on the fact that Brønsted acids present excellent catalytic activity for this intermolecular esterification reaction and Brønsted acidic ionic liquids have been successfully used as catalyst in organic syntheses [29-31], we designed a series of Brønsted acidic ionic liquids and applied them as catalysts for the preparation of oligomeric ricinoleic acid from ricinoleic acid to develop a facile synthesis and separation protocol. Gratifyingly, the IL $\left[\mathrm{HSO}_{3}-\mathrm{BDBU}\right] \mathrm{H}_{2} \mathrm{PO}_{4}$ showed to be efficient both in synthesis and product separation [32]. Through process parameter selection, it was found that a product with different acid value can be obtained by changing the reaction time at $190{ }^{\circ} \mathrm{C}$ and $50 \mathrm{kPa}$ with $15 \mathrm{wt} \%$ IL as catalyst. The viscosity characterization showed the product derived from $6 \mathrm{~h}$ of reaction, whose acid value is $51 \mathrm{mg} \mathrm{KOH} / \mathrm{g}$ and the corresponding average oligomerization degree is 4 , meets the requirement of lubricant additive index. Notably, after reaction, the product and IL catalyst can be easily separated by phase separation and the recovered catalyst can be used at least for five cycles without obvious deactivation, which shows tremendous advantage for large-scale industrial application. The reaction and separation procedures are depicted in Scheme 1.

\section{Results and Discussion}

Considering protic acids have catalytic effects on the esterification reaction, we designed and synthesized a series of ILs containing protic anions as shown in Scheme 2. With the synthesized ILs as catalyst, the ricinoleic acid esterification was performed and the catalytic activity of these functional ILs was evaluated with the acid value of the product as it is a convenient index to monitor the degree of oligomerization by reflecting the concentration of carboxy groups in the system, which has been cross verified by HPLC method [19,28].

The results showed that the protic anion is necessary for the intermolecular esterification as no catalytic activity can be ob- 

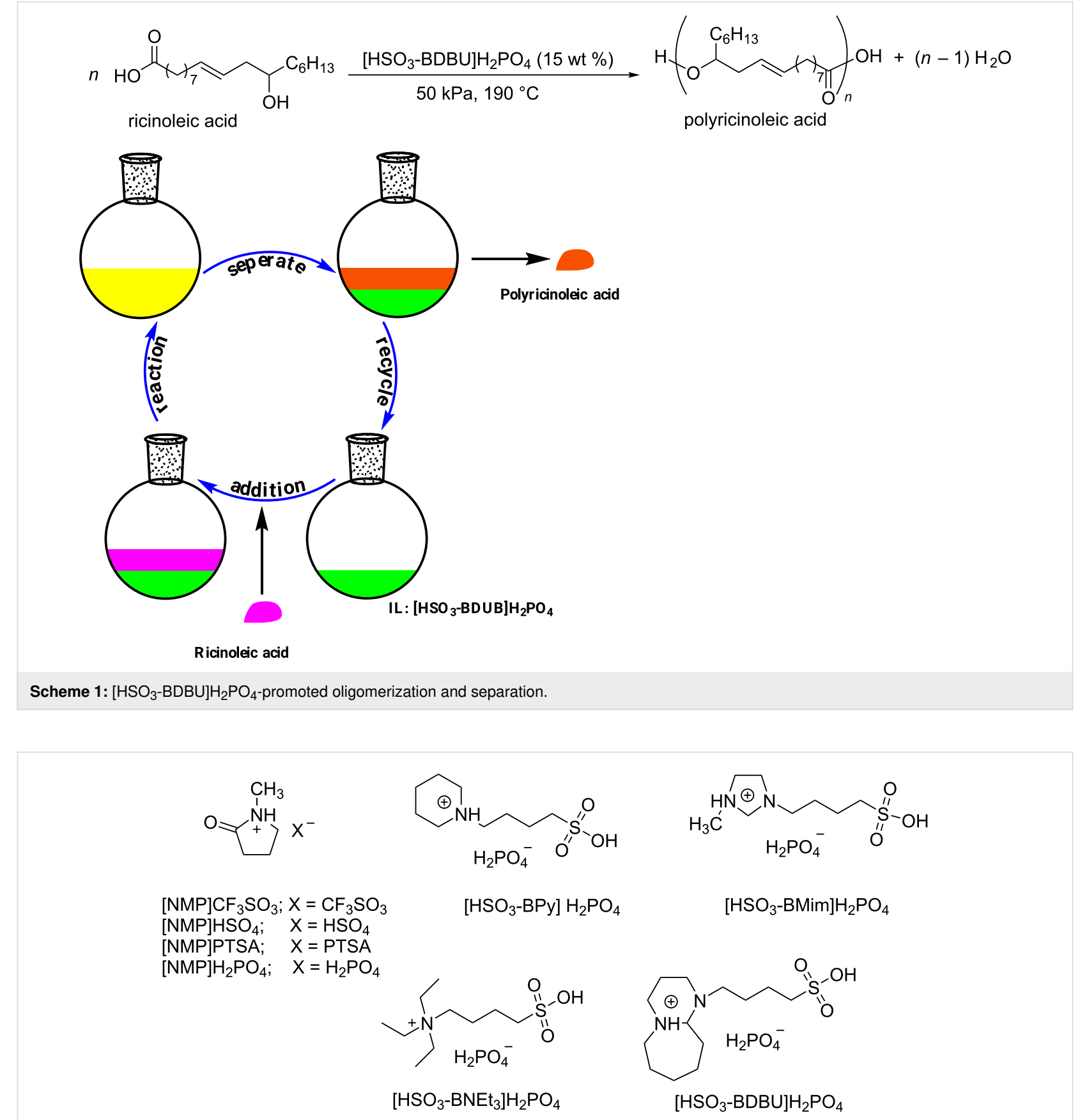

Scheme 2: Structures of ILs used in this work.

served for the IL with aprotic anion (Table 1, entries 1 and 2). For the ILs containing protic anions, the ILs containing polyprotic anions are more conducive to esterification (Table 1, entries 1-4 vs 5), which may originate from its higher proton concentration in the reaction system. With $\mathrm{H}_{2} \mathrm{PO}_{4}{ }^{-}$as anion, the ILs containing different cations were then synthesized and their catalytic activity on the esterification reaction was investigated. The results (Table 1, entries 5-9) revealed that the cation also affected the catalytic activity of the IL. Taking the decrease of acid value as catalytic activity index, the ionic liquid 1-butanesulfonic acid triethylamine dihydrogen phosphate $\left(\left[\mathrm{HSO}_{3}{ }^{-}\right.\right.$ $\left.\mathrm{BNEt}_{3}\right] \mathrm{H}_{2} \mathrm{PO}_{4}$ ) performed best among the tested ionic liquids in this study (Table 1 , entry 8 ). However, the IL $\left[\mathrm{HSO}_{3}\right.$ BDBU] $\mathrm{H}_{2} \mathrm{PO}_{4}$ showed a much more attractive feature in product separation as stratification of product and catalyst was observed in the flask within a few minutes after reaction (Table 1, entry 9). Therefore, the IL $\left[\mathrm{HSO}_{3}-\mathrm{BDBU}\right] \mathrm{H}_{2} \mathrm{PO}_{4}$ not only acts as an efficient catalyst but also provides a facile protocol for 
Table 1: Screening of ILs in the esterification of ricinoleic acid ${ }^{\mathrm{a}}$.

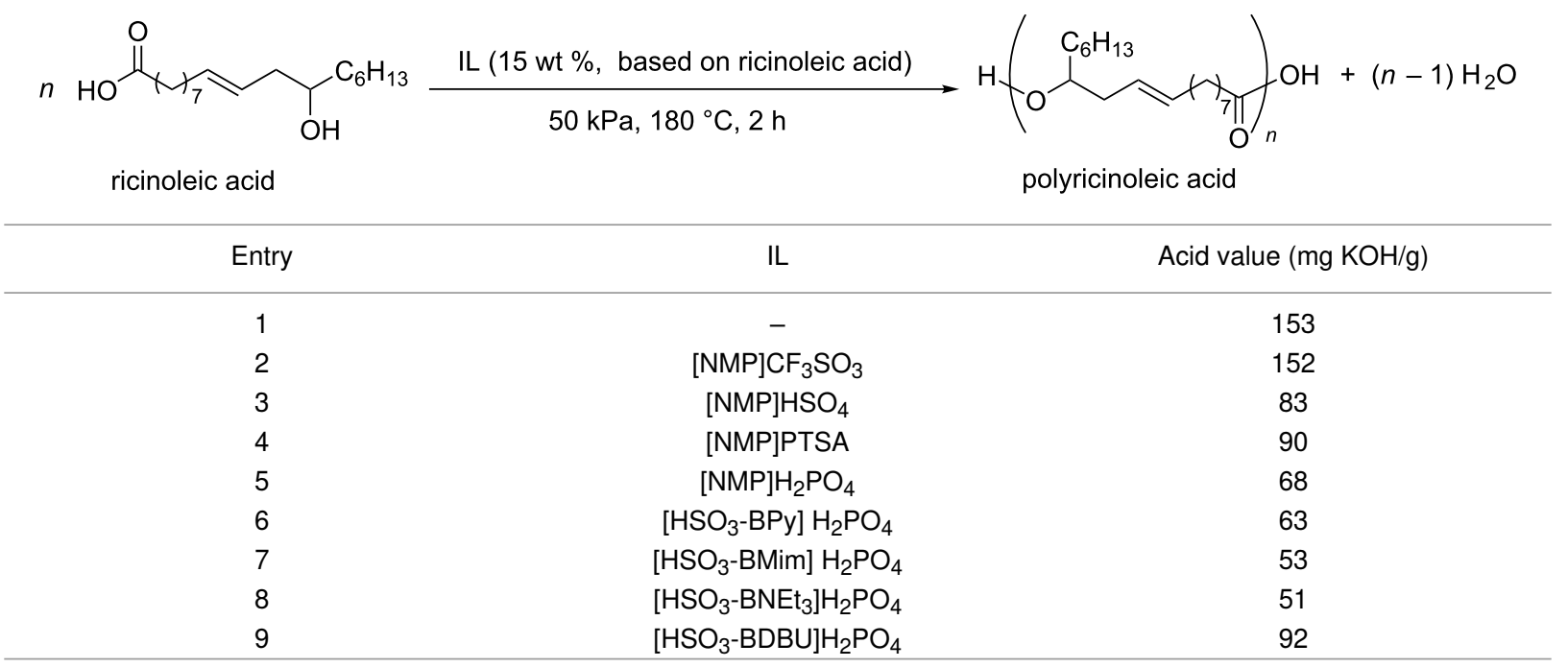

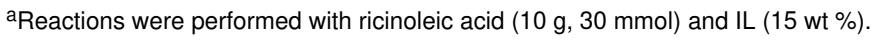

product and catalyst separation and thus avoids the workup procedure. In this context, $\left[\mathrm{HSO}_{3}-\mathrm{BDBU}\right] \mathrm{H}_{2} \mathrm{PO}_{4}$ was selected as the suitable catalyst for further investigations.

Having selected the IL $\left[\mathrm{HSO}_{3}-\mathrm{BDBU}\right] \mathrm{H}_{2} \mathrm{PO}_{4}$ as catalyst, the process optimization was performed to further promote the intermolecular dehydration esterification. The reaction temperature, catalyst loading, and vacuum degree on the reaction outcome were in detail investigated and the acid value of the product was used to evaluate the reaction results (Table 2). It was easily found that a higher temperature was favorable for the formation of oligomeric ricinoleic acid (Table 2, entries 1-5).

Table 2: Optimization of the key reaction parameters ${ }^{\mathrm{a}}$.

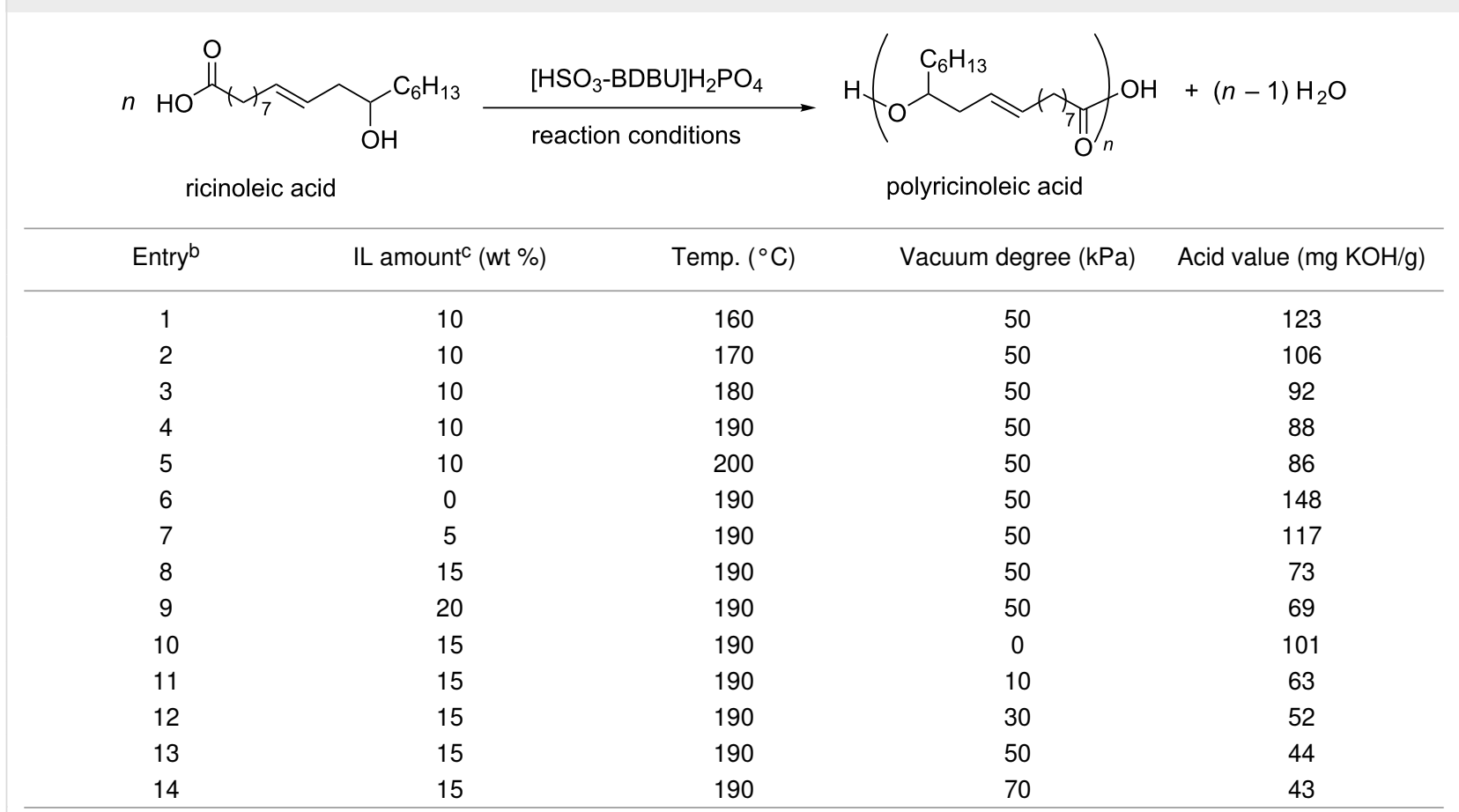

aStandard reaction conditions: ricinoleic acid $(10 \mathrm{~g}, 30 \mathrm{mmol})$ and different amount of $\mathrm{IL}$ at a variety of temperature and vacuum degree; ${ }^{\mathrm{b}}$ reaction time, $2 \mathrm{~h}$ (entries 1-9), $8 \mathrm{~h}$ (entries 10-14); Cbased on ricinoleic acid. 
When the temperature was $190{ }^{\circ} \mathrm{C}$, the acid value dropped to $88 \mathrm{mg} \mathrm{KOH} / \mathrm{g}$ in $2 \mathrm{~h}$. Further increasing the reaction temperature cannot lead to a significant drop of acid value. Thus, $190{ }^{\circ} \mathrm{C}$ was selected as the suitable reaction temperature. With the optimal reaction temperature, the amount of catalyst was studied at $190{ }^{\circ} \mathrm{C}$ and a vacuum degree of $50 \mathrm{kPa}$ (Table 2, entries 6-9). As expected, the introduction of $\left[\mathrm{HSO}_{3}-\right.$ BDBU] $\mathrm{H}_{2} \mathrm{PO}_{4}$ can improve the intramolecular esterification greatly compared with the scenario without catalyst and the catalyst loading has a positive effect on the oligomerization degree. When the amount of $\left[\mathrm{HSO}_{3}-\mathrm{BDBU}\right] \mathrm{H}_{2} \mathrm{PO}_{4}$ exceeded $15 \mathrm{wt} \%$ relative to ricinoleic acid, the catalytic efficiency was almost unchanged. Therefore, the optimum amount of catalyst was determined to be $15 \mathrm{wt} \%$ in the following investigation.

The vacuum degree is another factor to affect the intermolecular esterification as different vacuum degree can result in a different water removal rate, which may lead to a different equilibrium toward estolides product. Five different levels of vacuum degrees were applied to the reaction system, the results showed the oligomerization degree increased with increasing vacuum degree (Table 2, entries 10-14). A stable acid value was approached when the vacuum degree was higher than $50 \mathrm{kPa}$. Consequently, $50 \mathrm{kPa}$ was select as a suitable vacuum degree.

According to the above results, the suitable conditions for the esterification of ricinoleic acid were set at $190{ }^{\circ} \mathrm{C}$ under a vacuum degree of $50 \mathrm{kPa}$ and with $15 \mathrm{wt} \%\left[\mathrm{HSO}_{3}-\right.$ $\mathrm{BDBU}] \mathrm{H}_{2} \mathrm{PO}_{4}$ as catalyst. Under the selected conditions, the acid value versus reaction time was inspected by sampling every $2 \mathrm{~h}$ (Table 3 , entries $2-10$ ). Simultaneously, the ${ }^{1} \mathrm{H}$ NMR spectra of the samples in $\mathrm{CDCl}_{3}$ were also examined. In the ${ }^{1} \mathrm{H}$ NMR study, a peak found at $3.62 \mathrm{ppm}$ gradually disappeared and a new peak at $4.88 \mathrm{ppm}$ appeared (Figure 1). This is associated with the changes of the chemical environment for the
$\mathrm{C}_{12}$ - $\mathrm{H}$ bond. That is, in ricinoleic acid $\left(l_{1}\right.$, Figure 1$)$, the $\mathrm{C}_{12}$ is attached to the hydroxy group while in the corresponding ester product $\left(l_{2-10}\right.$, Figure 1$), \mathrm{C}_{12}$ is linked to the ester bond, thereby resulting in a change in the chemical shift of $\mathrm{H}$ connected with $\mathrm{C}_{12}$. As the chemical shift of $\mathrm{H}$ in methyl at $0.87 \mathrm{ppm}$ does not change before and after the reaction, it is used as reference and the peak integral ratio of $\mathrm{C}_{12}-\mathrm{H}\left(\mathrm{A}_{n}\right)$ to methyl-H $\left(\mathrm{A}_{m}\right)$ in the ${ }^{1} \mathrm{H}$ NMR spectra is used to determine the oligomerization degree. Theoretically, oligomeric ricinoleic acids with different oligomerization degree have their characteristic $\mathrm{A}_{n} / \mathrm{A}_{m}$ values as listed in Table 3. For a specific sample, both the peaks for $\mathrm{C}_{12}-\mathrm{H}$ and for methyl-H were integrated and the ratio of $\mathrm{A}_{n} / \mathrm{A}_{m}$ was calculated. Then the resulting value was compared with the theoretical ones to determine the oligomerization degree of the product. It should be noted that this calculation is based on the assumption that the oligomerization degree of the product is monodisperse. Actually, the obtained oligomerization degree is the average oligomerization degree. By adopting the index $\mathrm{A}_{n} / \mathrm{A}_{m}$, the relationship of acid value and oligomerization degree can be constructed. According to the ${ }^{1} \mathrm{H}$ NMR results, the value $A_{n} / A_{m}$ increased as the reaction proceeded (Table 3, entries $2-10$ vs entry 1 ), which means that the average oligomerization degree of oligomeric ricinoleic acid can be adjusted by changing the reaction time.

For oligomeric ricinoleic acid, its physicochemical properties depend on the oligomerization degree. In order to be used as lubriant in metal-working fluid, the viscosity and the viscosity index of oligomeric ricinoleic acid should fall into the acceptable scope according to Hostagliss L4 oil soluble lubricant additive product index. To determine the suitable reaction time and obtain the qualified product, the viscosity and viscosity index of samples derived from $4 \mathrm{~h}, 6 \mathrm{~h}$ and $8 \mathrm{~h}$ of reaction (i.e. NK-A, $\mathrm{NK}-\mathrm{B}$ and NK-C) were further measured and the results are compared with the commercial product Hostagliss L4 (Table 4).

\begin{tabular}{|c|c|c|c|c|c|}
\hline Entry & $\begin{array}{l}\text { Reaction time } \\
\text { (h) }\end{array}$ & $\begin{array}{l}\text { Acid value } \\
(\mathrm{mg} \mathrm{KOH} / \mathrm{g})\end{array}$ & $\begin{array}{l}\text { Experimental } \\
\qquad A_{n} / A_{m}\end{array}$ & $\begin{array}{l}\text { Theoretical } \\
\mathrm{A}_{n} / \mathrm{A}_{m}\end{array}$ & $\begin{array}{c}\text { Average oligomerization } \\
\text { degree }\end{array}$ \\
\hline 1 & 0 & 162 & - & - & - \\
\hline 2 & 2 & 73 & 0.1682 & 0.1670 & 2 \\
\hline 3 & 4 & 60 & 0.2219 & 0.2220 & 3 \\
\hline 4 & 6 & 51 & 0.2530 & 0.2500 & 4 \\
\hline 5 & 8 & 44 & 0.2680 & 0.2670 & 5 \\
\hline 6 & 10 & 38 & 0.2781 & 0.2780 & 6 \\
\hline 7 & 12 & 32 & 0.2861 & 0.2857 & 7 \\
\hline 8 & 14 & 26 & 0.2915 & 0.2917 & 8 \\
\hline 9 & 16 & 21 & 0.2963 & 0.2963 & 9 \\
\hline 10 & 18 & 17 & 0.2999 & 0.3000 & 10 \\
\hline
\end{tabular}

aThe ricinoleic acid with an acid value of $162 \mathrm{mg} \mathrm{KOH} / \mathrm{g}$ was used as raw material and interval sampling was performed every $2 \mathrm{~h}$. 


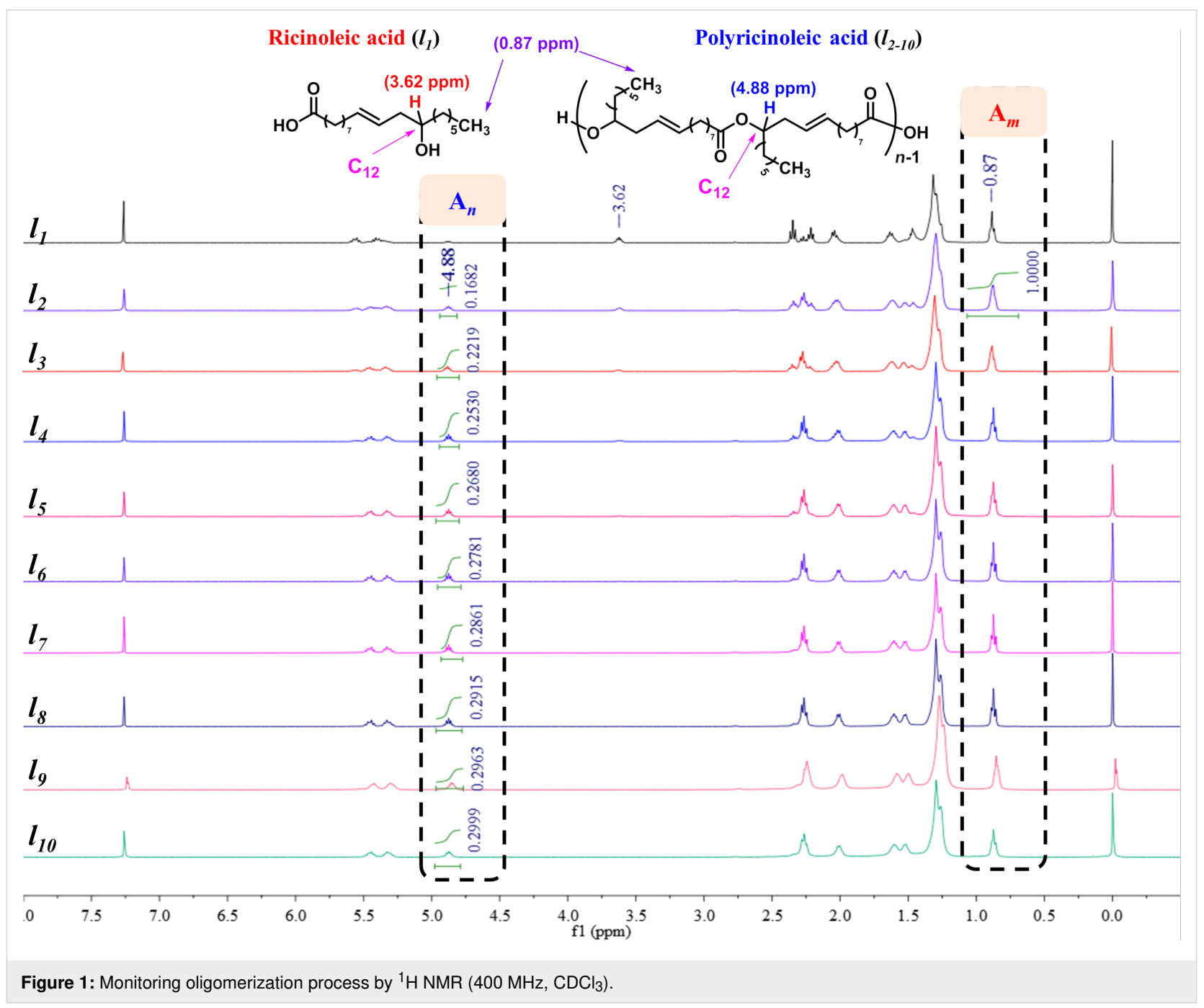

Table 4: Physicochemical properties of oligomeric ricinoleic acid compared to Hostagliss L4.

\begin{tabular}{|c|c|c|c|c|c|}
\hline \multirow{2}{*}{ Entry } & \multirow{2}{*}{ Sample } & \multirow{2}{*}{ Acid value $(\mathrm{mg} \mathrm{KOH} / \mathrm{g})$} & \multicolumn{2}{|c|}{ Viscosity $\left(\mathrm{mm}^{2} / \mathrm{s}\right)$} & \multirow{2}{*}{ Viscosity index } \\
\hline & & & $40^{\circ} \mathrm{C}$ & $100^{\circ} \mathrm{C}$ & \\
\hline 1 & Hostagliss L4 & 52 & 400 & 45 & 169 \\
\hline 2 & NK-A & 60 & 373 & 39 & 154 \\
\hline 3 & NK-B & 51 & 408 & 46 & 171 \\
\hline 4 & NK-C & 44 & 514 & 53 & 167 \\
\hline
\end{tabular}

As the results listed, NK-B meets the specifications of lubricant, which indicated that $6 \mathrm{~h}$ of reaction under the catalysis of $\left[\mathrm{HSO}_{3}-\mathrm{BDBU}\right] \mathrm{H}_{2} \mathrm{PO}_{4}$ can afford the standard-compliant biolubricant oligomeric ricinoleic acid.

\section{Reusability of $\left[\mathrm{HSO}_{3}-\mathrm{BDBU}\right] \mathrm{H}_{2} \mathrm{PO}_{4}$}

As the IL catalyst $\left[\mathrm{HSO}_{3}-\mathrm{BDBU}\right] \mathrm{H}_{2} \mathrm{PO}_{4}$ is immiscible with the product at room temperature, stratification occurs after reaction, thus renders an easy catalyst recyclability and product separation. After decanting the upper product and washing the remaining IL with a small amount of dichloromethane, the weight of $\left[\mathrm{HSO}_{3}-\mathrm{BDBU}\right] \mathrm{H}_{2} \mathrm{PO}_{4}$ was examined and then the fresh ricinoleic acid was added for the next cycle synthesis of oligomeric ricinoleic acid. The IL catalyst was used in five cycles of reaction and the resulting acid value of the product in each cycle was presented in Figure 2 along with the weight of 


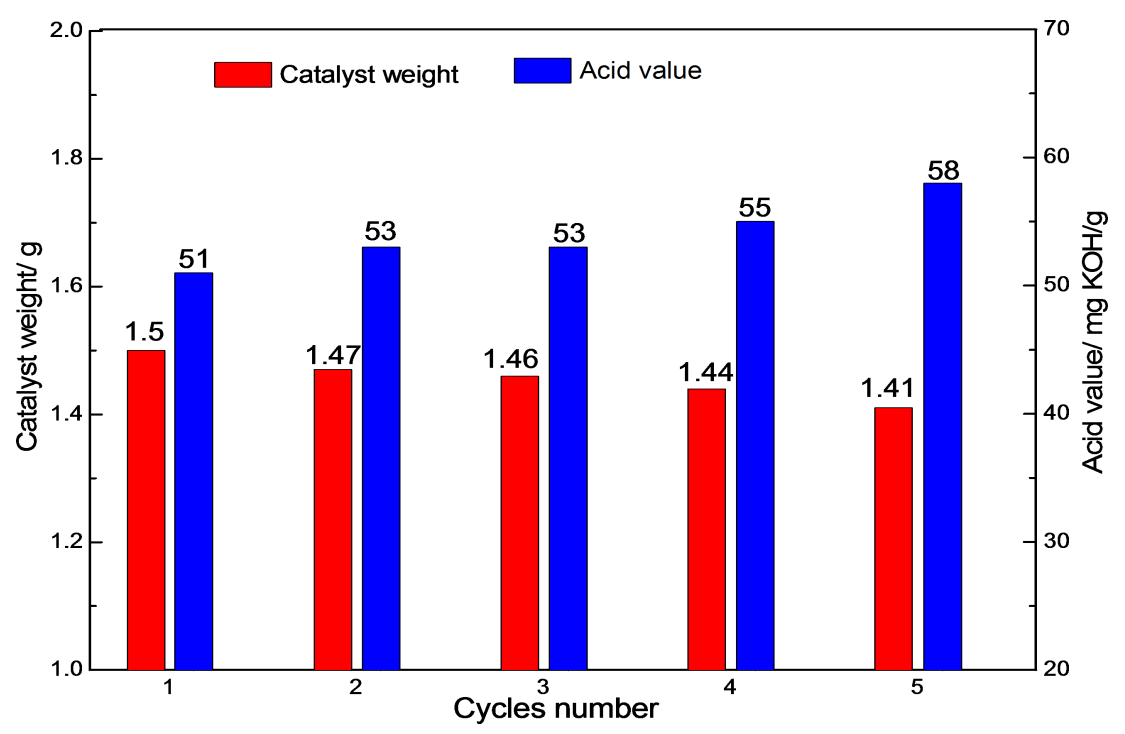

Figure 2: Reusability of the IL catalyst. Reaction conditions: $10 \mathrm{~g}(30 \mathrm{mmol})$ ricinoleic acid, $190{ }^{\circ} \mathrm{C}, 6 \mathrm{~h}, 50 \mathrm{kPa}$.

catalyst. It can be seen that $\left[\mathrm{HSO}_{3}-\mathrm{BDBU}\right] \mathrm{H}_{2} \mathrm{PO}_{4}$ can be utilized repeatedly for at least five times and only a slight decrease in catalytic activity was observed, which may be due to the weight loss of the recovered catalyst. To check the stability of the $\left[\mathrm{HSO}_{3}-\mathrm{BDBU}\right] \mathrm{H}_{2} \mathrm{PO}_{4}$ during reusability, the ${ }^{1} \mathrm{H}$ NMR of
$\left[\mathrm{HSO}_{3}-\mathrm{BDBU}\right] \mathrm{H}_{2} \mathrm{PO}_{4}$ was examined after five cycles of reaction and the results were presented in Figure 3. It can be seen that the IL catalyst was stable during the reaction as the spectrum remained basically unchanged compared with the fresh catalyst.

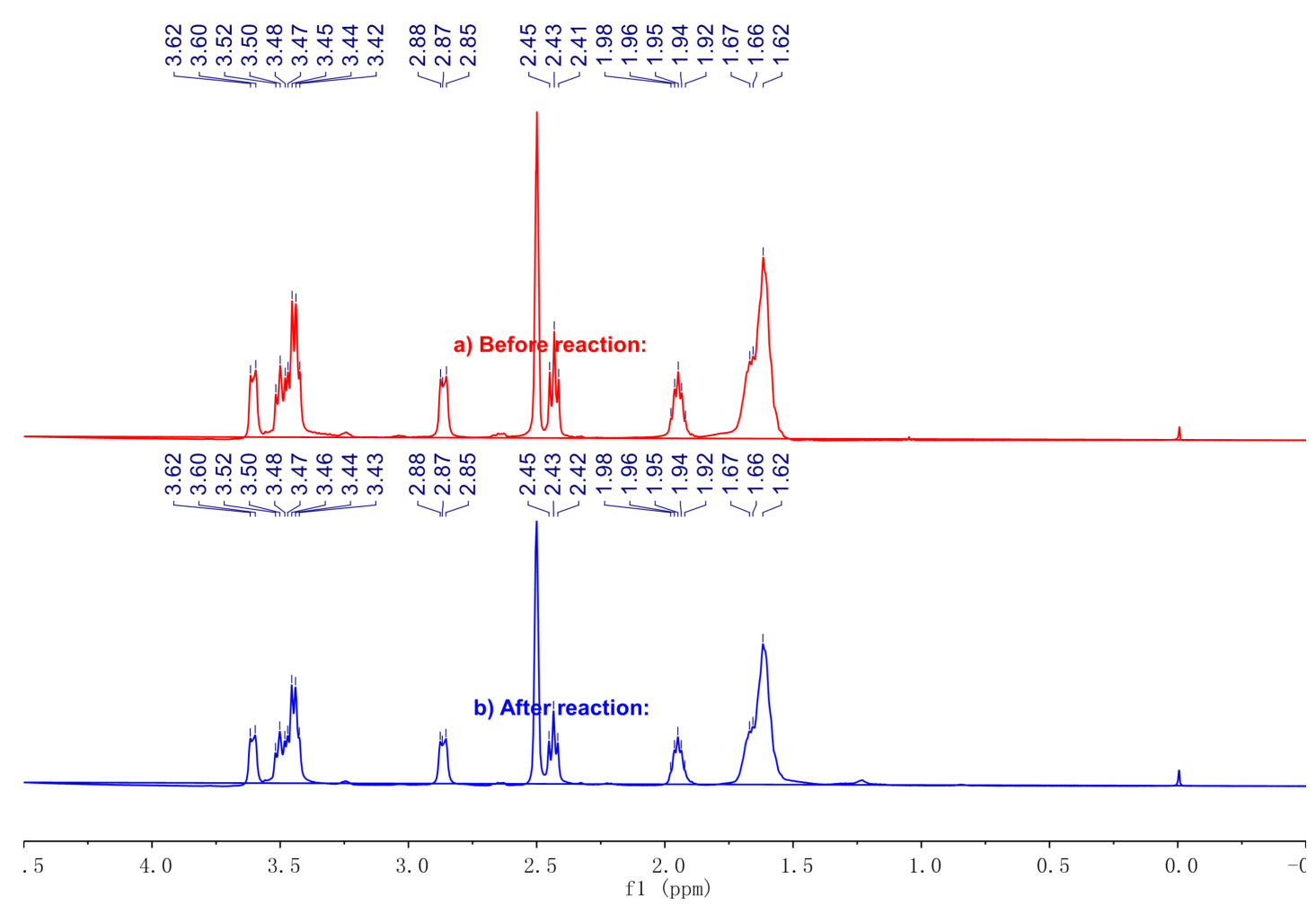

Figure 3: ${ }^{1} \mathrm{H}$ NMR $\left(400 \mathrm{MHz}\right.$, DMSO- $\left.d_{6}\right)$ spectra of $\left[\mathrm{HSO}_{3}-\mathrm{BDBU}\right] \mathrm{H}_{2} \mathrm{PO}_{4}$ : a) Fresh one; b) used one after five cycles. 


\section{Proposed mechanism}

According to our experimental results, the protic acid is crucial for the reaction. Therefore, it is inferred that the reaction undergoes proton-promoted intermolecular esterification and the reaction mechanism with catalyst $\left[\mathrm{HSO}_{3}-\mathrm{BDBU}\right] \mathrm{H}_{2} \mathrm{PO}_{4}$ is depicted in Scheme 3. Firstly, the Brønsted acidic IL $\left[\mathrm{HSO}_{3}-\right.$ BDBU $\mathrm{H}_{2} \mathrm{PO}_{4}$ activates the carbonyl group of ricinoleic acid, leading to the generation of intermediate A. Concurrently, the hydroxy group in another ricinoleic acid molecule may be activated by the cation of IL and attacks the intermediate A (step I), generating a tetrahedral intermediate B. Finally, dehydration and deprotonation of the tetrahedral intermediate occurs (step II), forming dimeric ricinoleic acid C. The carboxyl and hydroxy groups in the dimeric ricinoleic acid may further undergo esterification, providing the oligomeric ricinoleic acid with different oligomerization degree.

\section{Conclusion}

To conclude, a highly efficient Brønsted acidic IL catalyst $\left[\mathrm{HSO}_{3}-\mathrm{BDBU}\right] \mathrm{H}_{2} \mathrm{PO}_{4}$ was developed for the esterification of ricinoleic acid. The reaction performed well under solvent-free conditions, the qualified biolubricant oligomeric ricinoleic acid can be prepared at $190{ }^{\circ} \mathrm{C}$ and under vacuum degree of $50 \mathrm{kPa}$ with $15 \mathrm{wt} \% \mathrm{IL}$ as catalyst in $6 \mathrm{~h}$. Both the acid value and average oligomerization degree of the product were determined and it was found the acid value was $51 \mathrm{mg} \mathrm{KOH} / \mathrm{g}$ and the average

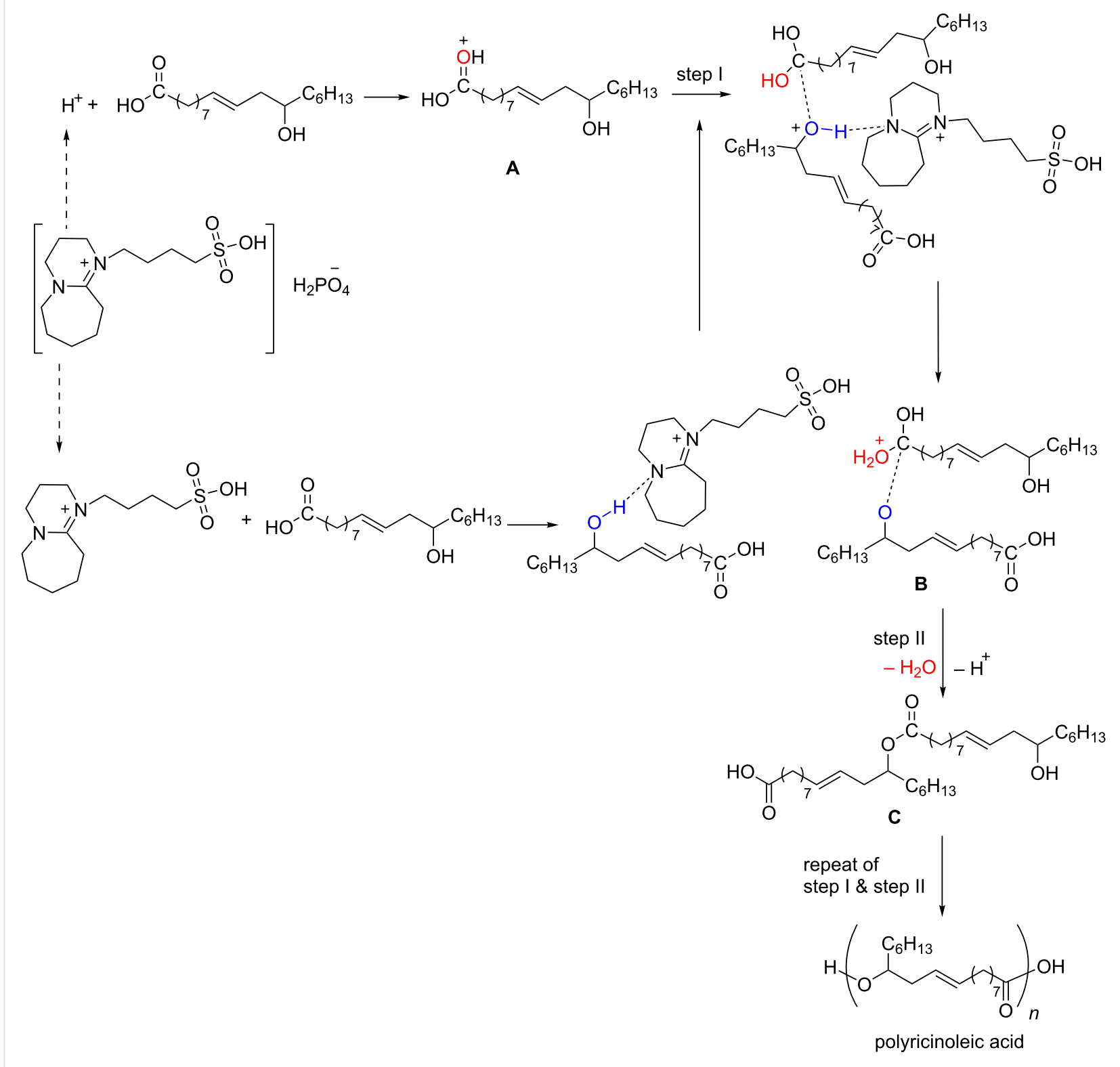


oligomerization degree was 4 . The reaction has excellent selectivity and no other byproducts were detected except water. More remarkably, a simple stratifying at room temperature will cause the separation of catalyst and product, which means the additional solvent extraction or distillation separation employed in the traditional IL catalysis was unnecessary in this system. Besides, the catalyst can be reused at least for five cycles without significant activity lost. Therefore, this protocol employing the Brønsted acidic ionic liquid as catalyst represents a green synthesis method for oligomeric ricinoleic acid and can be run in environmentally manner. It is a promising candidate for the commercial production of oligomeric ricinoleic acid from ricinoleic acid.

\section{Experimental Preparation procedure of $\left[\mathrm{HSO}_{3}-\right.$ $\mathrm{BDBU}] \mathrm{H}_{2} \mathrm{PO}_{4}$}

To prepare the IL $\left[\mathrm{HSO}_{3}-\mathrm{BDBU}^{\mathrm{H}} \mathrm{H}_{2} \mathrm{PO}_{4}, 0.1 \mathrm{~mol}\right.$ (13.6 g) 1,4butane sultone was mixed with $0.1 \mathrm{~mol}(15.2 \mathrm{~g})$ 1,8-diazobicyclo[5,4,0]undec-7-ene (DBU) in a flask containing $50 \mathrm{~mL}$ of acetonitrile. After $24 \mathrm{~h}$ reflux at $80^{\circ} \mathrm{C}$, the reaction mixture was cooled to room temperature. Then $30 \mathrm{~mL}$ diethyl ether was added to the reaction mixture to precipitate the product. After that, the precipitate was collected by filtration and washed twice with diethyl ether. The resulting light yellow precipitate was then dried in vacuum at $60^{\circ} \mathrm{C}$ for $4 \mathrm{~h}$. Afterwards, the aqueous solution containing a stoichiometric amount of phosphoric acid was added dropwise to $50 \mathrm{~mL} \mathrm{CH}_{2} \mathrm{Cl}_{2}$ containing $0.05 \mathrm{~mol}$ $(14.4 \mathrm{~g})\left[\mathrm{HSO}_{3}-\mathrm{BDBU}\right]$ and stirred at $60{ }^{\circ} \mathrm{C}$ for $4 \mathrm{~h}$, forming a viscous liquid on the surface of $\mathrm{CH}_{2} \mathrm{Cl}_{2}$ which can be easily separated by centrifugation. Then the viscous liquid was washed twice with $\mathrm{CH}_{2} \mathrm{Cl}_{2}$ and dried at $100{ }^{\circ} \mathrm{C}$ for $12 \mathrm{~h}$, obtaining $18.6 \mathrm{~g}$ yellow viscous liquid with the yield of $96 \%$. The resulting compound was identified to be IL $\left[\mathrm{HSO}_{3}\right.$ BDBU] $\mathrm{H}_{2} \mathrm{PO}_{4} \cdot{ }^{1} \mathrm{H}$ NMR (400 MHz, DMSO- $\left.d_{6}\right) \delta 1.62-1.67$ (m, 10H), 1.92-1.98 (m, 2H), 2.41-2.45 (t, $J=6.8 \mathrm{~Hz}, 2 \mathrm{H})$, $2.85-2.88$ (t, $J=4.8,2 \mathrm{H}), 3.42-3.62(\mathrm{~m}, 8 \mathrm{H}) \mathrm{ppm} ;{ }^{13} \mathrm{C} \mathrm{NMR}$ $\left(100 \mathrm{MHz}, \mathrm{DMSO}-d_{6}\right) \delta 19.65,22.13,22.88,25.55,27.12$, 27.22, 27.90, 46.58, 48.52, 50.65, 52.92, 53.98, 165.98 ppm; FTIR $(\mathrm{KBr}) v_{\max } / \mathrm{cm}^{-1}: 3317.18,2939.11,2867.62,1621.52$, 1527.51, 1452.10, 1328.75, 1201.00, 998.74, 726.90, 600.28; ESIMS (+) $\mathrm{m} / \mathrm{z}: 100.1,102.1,153.2,289.3,390.1$.

For the preparation of other ILs in this paper and for full experimental data see Supporting Information File 1.

\section{Catalytic dehydration esterification of ricinoleic acid and catalyst recycling}

The dehydration esterification of ricinoleic acid was investigated using ILs as catalyst. In a typical run, $10 \mathrm{~g}(30 \mathrm{mmol})$ ricinoleic acid and $1 \mathrm{~g}$ (2.6 mmol) $\left[\mathrm{HSO}_{3}-\mathrm{BDBU}_{2} \mathrm{H}_{2} \mathrm{PO}_{4}\right.$ were added into a $100 \mathrm{~mL}$ glass flask equipped with magnetic stirrer, a reflux condenser and connected with vacuum line. Then, under a stirrer rate of $500 \mathrm{r} / \mathrm{min}$, the temperature was increased to $190{ }^{\circ} \mathrm{C}$ to promote the esterification reaction. Simultaneously, the reaction run at $50 \mathrm{kPa}$ to remove the generated water. After $2 \mathrm{~h}$ of reaction, the reaction mixture was cooled to room temperature for stratifying. The supernatant was oligomeric ricinoleic acid and it could be decanted directly for further treatment and acid value analysis. The IL catalyst deposited in the lower layer can be washed with a small amount of dichloromethane to remove the residual oligoester. After that, the fresh ricinoleic acid was added for the second run reaction and the recovered catalyst can be used repeatedly.

\section{Product characterization}

The oligomeric ricinoleic acid is a yellow oily liquid, and all experiments have yields greater than $90 \%$, which are determined by weighing. The spectral results identified the product. ${ }^{1} \mathrm{H}$ NMR $\left(400 \mathrm{MHz}, \mathrm{CDCl}_{3}\right) \delta 0.85-0.88(\mathrm{t}, J=3.9 \mathrm{~Hz}, 3 \mathrm{H})$, $1.26-1.29(\mathrm{~m}, 16 \mathrm{H}), 1.51-1.60(\mathrm{~m}, 4 \mathrm{H}), 2.00-2.01(\mathrm{~m}, 2 \mathrm{H})$, 2.25-2.26 (m, 4H), 4.86-4.89 (m, 1H), 5.30-5.46 (m, 2H) ppm; ${ }^{13} \mathrm{C}$ NMR $\left(100 \mathrm{MHz}, \mathrm{CDCl}_{3}\right) \delta 14.08,22.58,25.11,25.35$, 27.20-27.35, 29.03-29.71, 31.75, 31.98, 33.62, 34.65, 73.69, 124.30, 132.51, $173.58 \mathrm{ppm}$; FTIR (KBr) $v_{\max } / \mathrm{cm}^{-1}: 3416.44$, $3010.55,2927.89,2855.81,1733.38,1711.66,1464.22$, 1245.41, 1183.74, 725.11; ESIMS (+) $m / z: 579.3,876.6$, 1139.7, 1437.8, 1716.9, 1997.1.

\section{Acid value determination}

The acid value of product was determined using a modified ASTM D664 method [33], in which about $1 \mathrm{~g}$ sample was

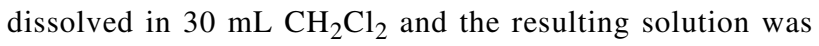
titrated against standard $0.1 \mathrm{~N}$ isopropanol $\mathrm{KOH}$. Acid value (mg KOH/g sample) was then calculated as follows:

$$
\text { acid value }=\frac{56.11 \cdot V \cdot C}{W}
$$

where $V(\mathrm{~mL})$ and $C(\mathrm{~mol} / \mathrm{L})$ are the consumed volume and concentration of $\mathrm{KOH}$ solution, respectively, $W(\mathrm{~g})$ is the weight of the sample.

To exclude the presence of IL in supernatant and ensure the reliability of acid value in oligomerization degree determination, additional treatment was performed for the supernatant before acid value determination. That is, the supernatant was diluted with dichloromethane, and the putative IL in the sample was extracted three times with distilled water. Then the remaining organic phase was dried with $\mathrm{Na}_{2} \mathrm{SO}_{4}$ for $24 \mathrm{~h}$ followed by filtration. After that, the filtrate was collected and the dichloromethane solvent was removed by vacuum evaporation 
to obtain oligomeric ricinoleic acid for acid value measurement (Table 5, entries 1, 3 and 5). On the other hand, the acid value of supernatant without any treatment was also determined for comparison (Table 5, entries 2, 4 and 6). The acid values of the two treatments were identical, indicating that IL settled well after the reaction and was absent in the product.

Table 5: Acid value measurement results of two different treatments for the supernatant.

\begin{tabular}{ccc} 
Entry $^{\mathrm{a}}$ & $\begin{array}{c}\text { Reaction time } \\
(\mathrm{h})\end{array}$ & $\begin{array}{c}\text { Acid value } \\
(\mathrm{mg} \mathrm{KOH} / \mathrm{g})\end{array}$ \\
\hline 1 & 1 & 108 \\
2 & 1 & 108 \\
3 & 2 & 74 \\
4 & 2 & 73 \\
5 & 4 & 60 \\
6 & 4 & 60 \\
\hline
\end{tabular}

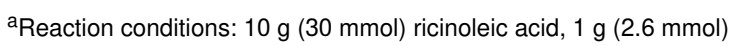
$\left[\mathrm{HSO}_{3}-\mathrm{BDBU}\right] \mathrm{H}_{2} \mathrm{PO}_{4}, 190{ }^{\circ} \mathrm{C}, 50 \mathrm{kPa}$.

\section{Supporting Information}

\section{Supporting Information File 1}

Experimental part and spectra of synthesized compounds. [https://www.beilstein-journals.org/bjoc/content/ supplementary/1860-5397-16-34-S1.pdf]

\section{Funding}

We thank the National Natural Science Foundation of China (21975135), Tianjin Nankai University Castor Engineering Science and Technology Co., Ltd. and Inner Mongolia Weiyu Biotech Co., Ltd. for financial support.

\section{ORCID ${ }^{\circledR}$ iDs}

Hong-Ru Li - https://orcid.org/0000-0002-4916-2815 Liang-Nian He - https://orcid.org/0000-0002-6067-5937

\section{References}

1. Ebata, H.; Yasuda, M.; Toshima, K.; Matsumura, S. J. Oleo Sci. 2008, 57, 315-320. doi:10.5650/jos.57.315

2. Alonso, D. M.; Bond, J. Q.; Dumesic, J. A. Green Chem. 2010, 12, 1493-1513. doi:10.1039/c004654j

3. Biermann, U.; Bornscheuer, U.; Meier, M. A. R.; Metzger, J. O.; Schäfer, H. J. Angew. Chem., Int. Ed. 2011, 50, 3854-3871. doi:10.1002/anie.201002767

4. Meier, M. A. R.; Metzger, J. O.; Schubert, U. S. Chem. Soc. Rev. 2007, 36, 1788-1802. doi:10.1039/b703294c

5. Miao, S.; Wang, P.; Su, Z.; Zhang, S. Acta Biomater. 2014, 10 , 1692-1704. doi:10.1016/j.actbio.2013.08.040
6. Biermann, U.; Friedt, W.; Lang, S.; Lühs, W.; Machmüller, G.; Metzger, J. O.; Rüsch gen. Klaas, M.; Schäfer, H. J.; Schneider, M. P. Angew. Chem., Int. Ed. 2000, 39, 2206-2224. doi:10.1002/1521-3773(20000703)39:13<2206::aid-anie2206>3.0.co;2$\mathrm{p}$

7. Nayak, P. L. J. Macromol. Sci., Rev. Macromol. Chem. Phys. 2000, 40, 1-21. doi:10.1081/mc-100100576

8. Thomas, A.; Matthäus, B.; Fiebig, H.-J. Ullmann's Encycl. Ind. Chem. 2000, 1-84. doi:10.1002/14356007.a10_173.pub2

9. Scarpa, A.; Guerci, A. J. Ethnopharmacol. 1982, 5, 117-137. doi:10.1016/0378-8741(82)90038-1

10. Mutlu, H.; Meier, M. A. R. Eur. J. Lipid Sci. Technol. 2010, 112, 10-30. doi:10.1002/ejlt.200900138

11. Ogunniyi, D. S. Bioresour. Technol. 2006, 97, 1086-1091. doi:10.1016/j.biortech.2005.03.028

12. Van der Steen, M.; Stevens, C. V. ChemSusChem 2009, 2, 692-713. doi:10.1002/cssc.200900075

13. Goodrum, J. W.; Geller, D. P. Bioresour. Technol. 2005, 96, 851-855. doi:10.1016/j.biortech.2004.07.006

14. Kim, H. T.; Baritugo, K.-A.; Oh, Y. H.; Hyun, S. M.; Khang, T. U.; Kang, K. H.; Jung, S. H.; Song, B. K.; Park, K.; Kim, I.-K.; Lee, M. O.; Kam, Y.; Hwang, Y. T.; Park, S. J.; Joo, J. C. ACS Sustainable Chem. Eng. 2018, 6, 5296-5305. doi:10.1021/acssuschemeng.8b00009

15. Borsotti, G.; Guglielmetti, G.; Spera, S.; Battistel, E. Tetrahedron 2001, 57, 10219-10227. doi:10.1016/s0040-4020(01)01057-2

16. Yoshida, Y.; Kawase, M.; Yamaguchi, C.; Yamane, T. J. Am. Oil Chem. Soc. 1997, 74, 261-267. doi:10.1007/s11746-997-0133-x

17. Hayes, D. G.; Kleiman, R. J. Am. Oil Chem. Soc. 1995, 72, 1309-1316. doi:10.1007/bf02546204

18. Zerkowski, J. A. Lipid Technol. 2008, 20, 253-256. doi:10.1002/lite.200800066

19. Vadgama, R. N.; Odaneth, A. A.; Lali, A. M. Heliyon 2019, 5, e01944. doi:10.1016/j.heliyon.2019.e01944

20. Bódalo-Santoyo, A.; Bastida-Rodríguez, J.; Máximo-Martín, M. F.; Montiel-Morte, M. C.; Murcia-Almagro, M. D. Biochem. Eng. J. 2005, 26, 155-158. doi:10.1016/j.bej.2005.04.012

21. Bódalo, A.; Bastida, J.; Máximo, M. F.; Montiel, M. C.; Gómez, M.; Murcia, M. D. Biochem. Eng. J. 2008, 39, 450-456. doi:10.1016/j.bej.2007.10.013

22. Bódalo, A.; Bastida, J.; Máximo, M. F.; Montiel, M. C.; Murcia, M. D.; Ortega, S. Biochem. Eng. J. 2009, 44, 214-219. doi:10.1016/j.bej.2008.12.007

23. Horchani, H.; Bouaziz, A.; Gargouri, Y.; Sayari, A. J. Mol. Catal. B: Enzym. 2012, 75, 35-42. doi:10.1016/j.molcatb.2011.11.007

24. Yoshida, Y.; Kawase, M.; Yamaguchi, C.; Yamane, T. J. Jpn. Oil Chem. Soc. 1995, 44, 328-333. doi:10.5650/jos1956.44.328

25. Erhan, S. M.; Kleiman, R.; Isbell, T. A. J. Am. Oil Chem. Soc. 1993, 70, 461-465. doi:10.1007/bf02542576

26. Zhang, Q.; Zhang, S.; Deng, Y. Green Chem. 2011, 13, 2619-2637. doi:10.1039/c1gc15334j

27. Petkovic, M.; Seddon, K. R.; Rebelo, L. P. N.; Silva Pereira, C. Chem. Soc. Rev. 2011, 40, 1383-1403. doi:10.1039/c004968a

28. Wang, G.; Sun, S. J. Oleo Sci. 2017, 66, 753-759. doi:10.5650/jos.ess17031

29. Li, M.; Wu, F.; Gu, Y. Chin. J. Catal. 2019, 40, 1135-1140. doi:10.1016/s1872-2067(19)63370-x 
30. El-Harairy, A.; Yiliqi; Lai, B.; Vaccaro, L.; Li, M.; Gu, Y. Adv. Synth. Catal. 2019, 361, 3342-3350.

doi:10.1002/adsc.201900246

31. El-Harairy, A.; Yiliqi; Yue, M.; Fan, W.; Popowycz, F.; Queneau, Y.; Li, M.; Gu, Y. ChemCatChem 2019, 11, 4403-4410.

doi:10.1002/cctc.201900784

32. Ye, F.; He, L. N.; You, F.; Li, H. R.; Wang, Q. R.; Gao, S.; He, X.;

Cui, X. Y. A protocol for oligomeric ricinoleic acid preparation and in-situ separation. Chin Patent CN202010124194.1, Feb 27, 2020.

33. ASTM D664-17; ASTM International: West Conshohocken, PA, 2017.

\section{License and Terms}

This is an Open Access article under the terms of the Creative Commons Attribution License

(https://creativecommons.org/licenses/by/4.0). Please note that the reuse, redistribution and reproduction in particular requires that the authors and source are credited.

The license is subject to the Beilstein Journal of Organic Chemistry terms and conditions:

(https://www.beilstein-journals.org/bjoc)

The definitive version of this article is the electronic one which can be found at: doi:10.3762/bjoc. 16.34 